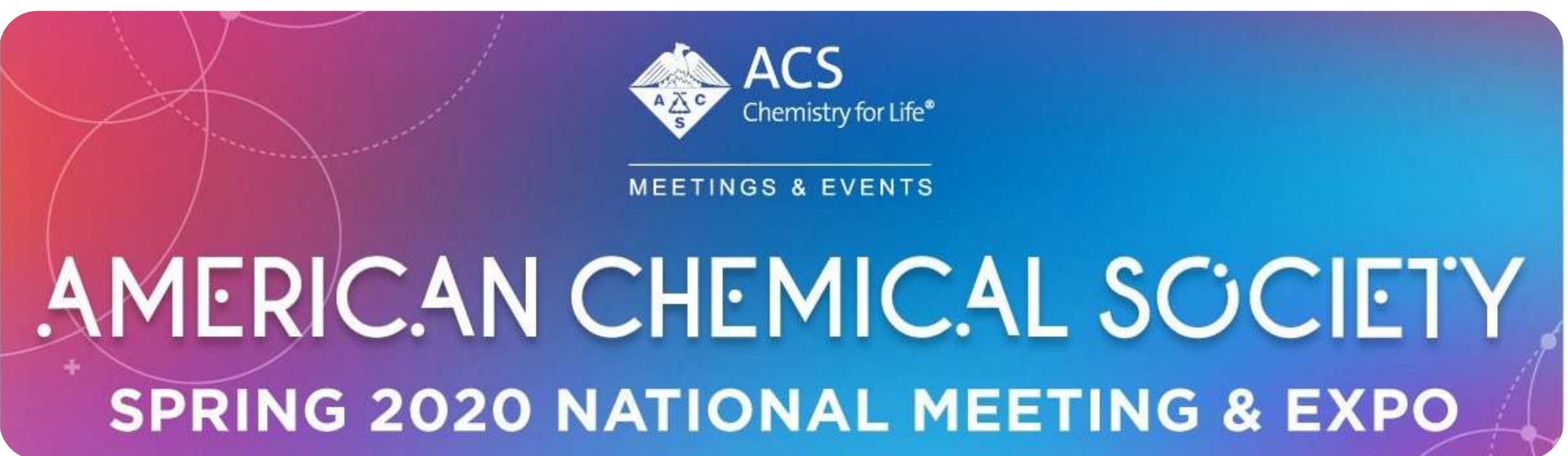

\title{
Organizing Distribution of Sulfonic Acid lonomer Using Elastin-Like Polypeptide
}

\author{
Presenter: Nuttanit Pramounmat
}

Authors: Nuttanit Pramounmat, Charles N. Loney, ChulOong Kim, Luke Wiles, Katherine E. Ayers, Ahmet Kusoglu, and Julie N. Renner 


\section{$\mathrm{H}_{2}$ Production by Water Electrolysis}

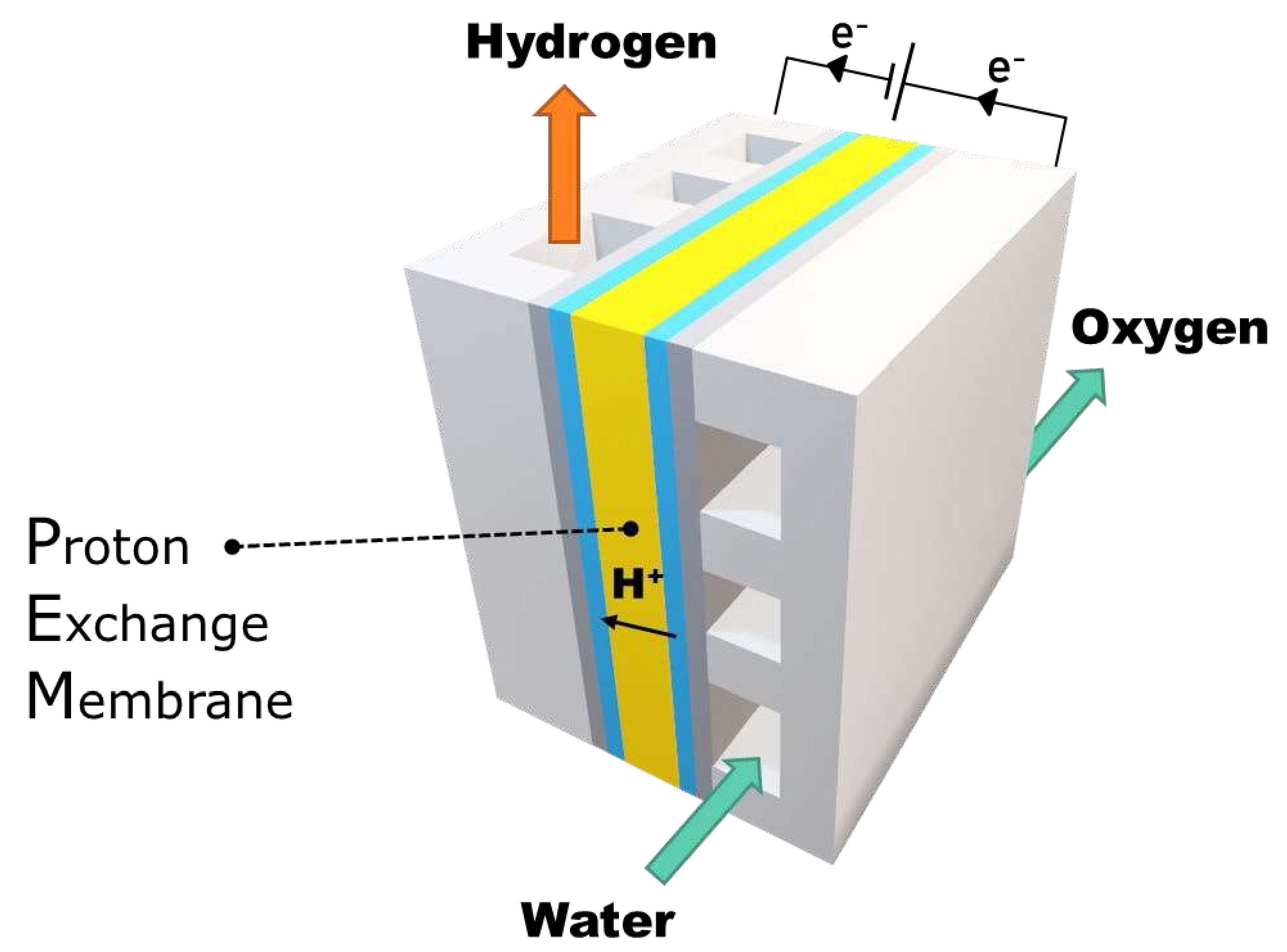




\section{Nafion ${ }^{\circledR}$ Ionomer (Perfluorinated sulfonic acid ionomer)}

is a part of both proton exchange membrane and catalyst layer

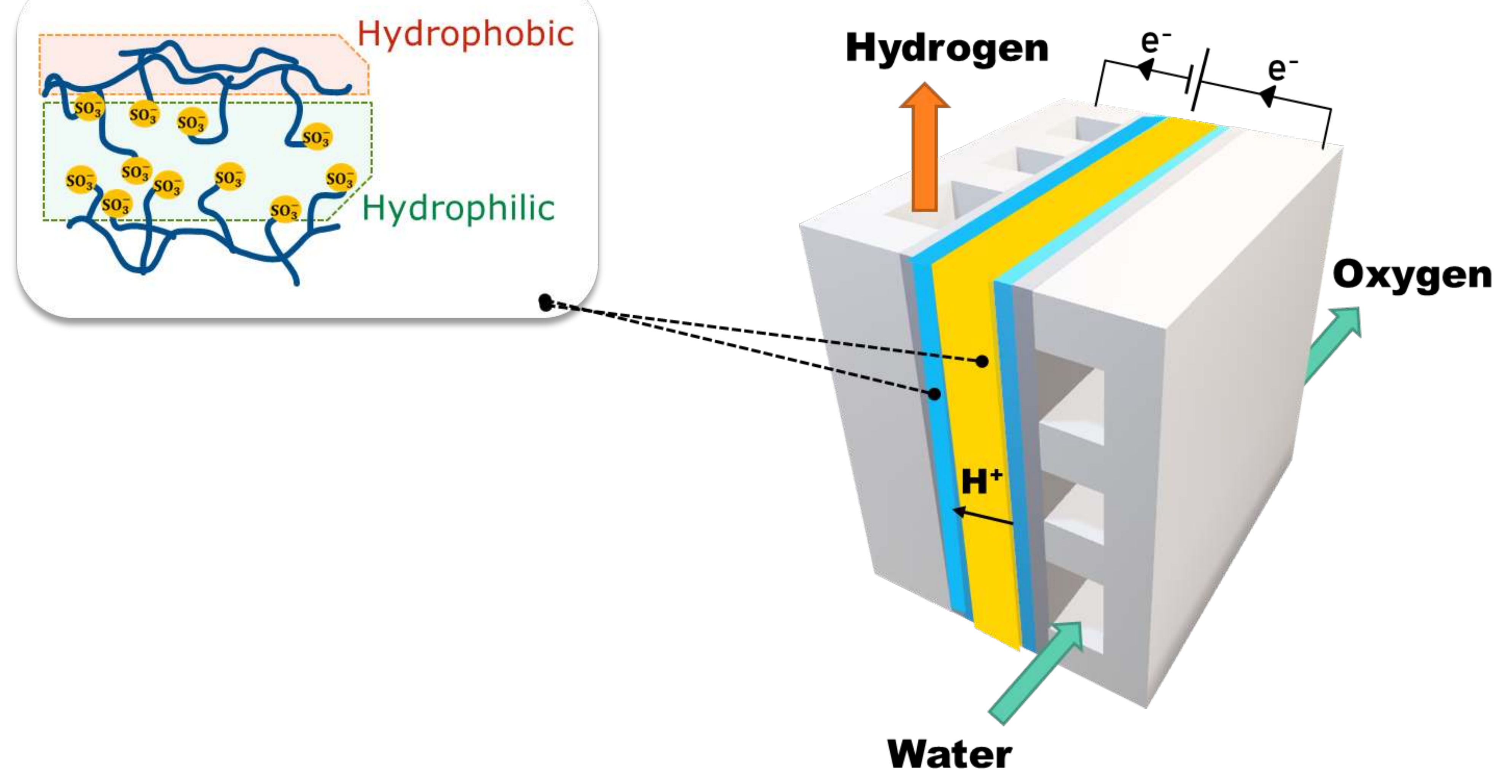




\section{Confinement causes transport issue}

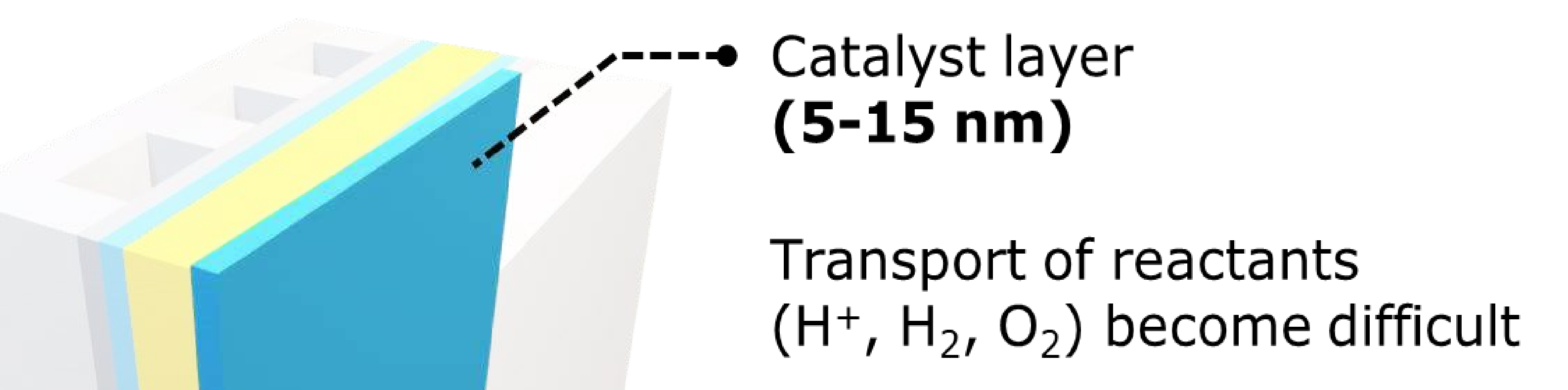




\section{Confinement causes transport issue}

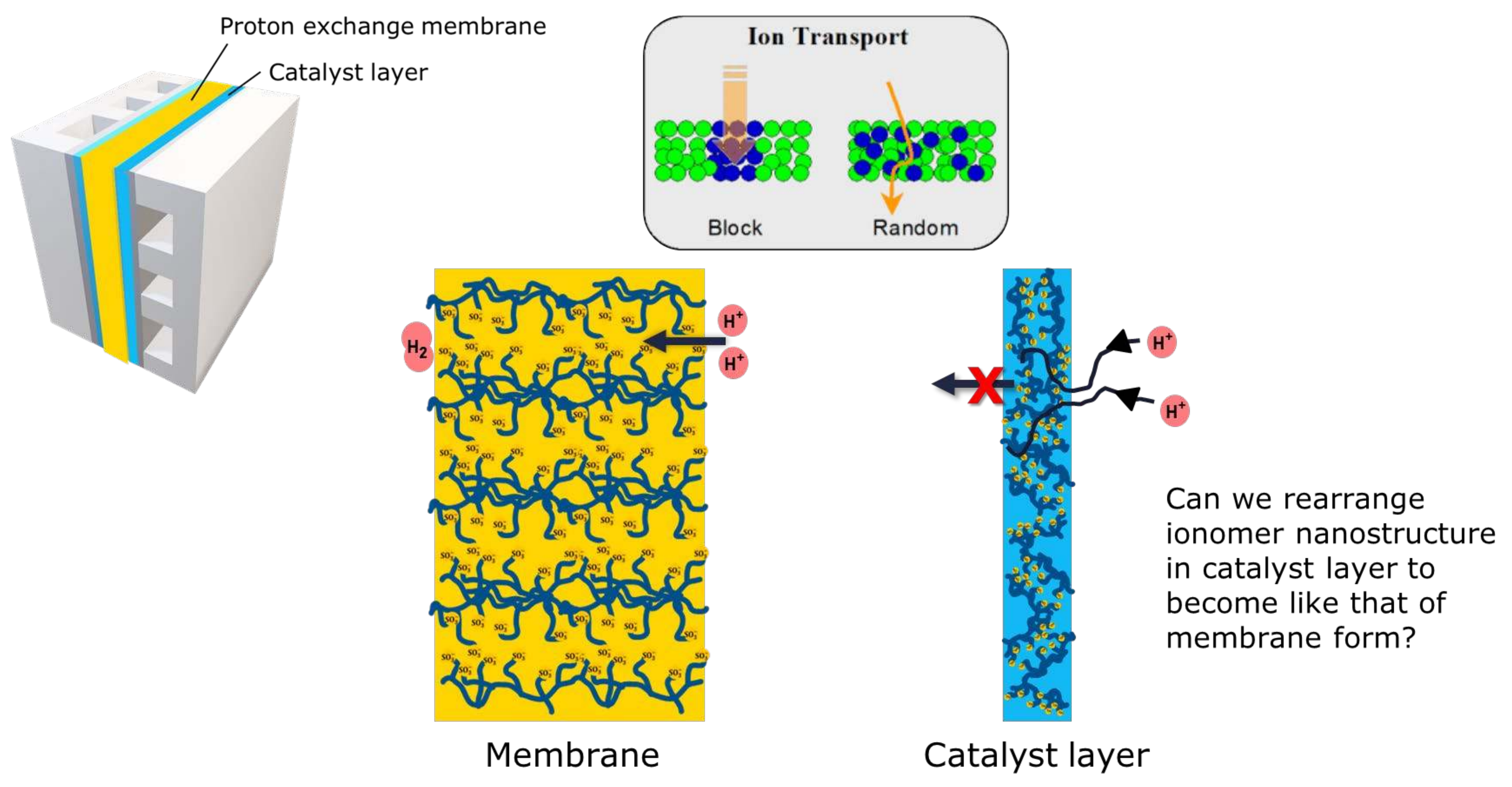




\section{Useful \& Tunable Materials}

For Nafion ${ }^{\circledR}$ film in catalyst layer $(<20 \mathrm{~nm})$

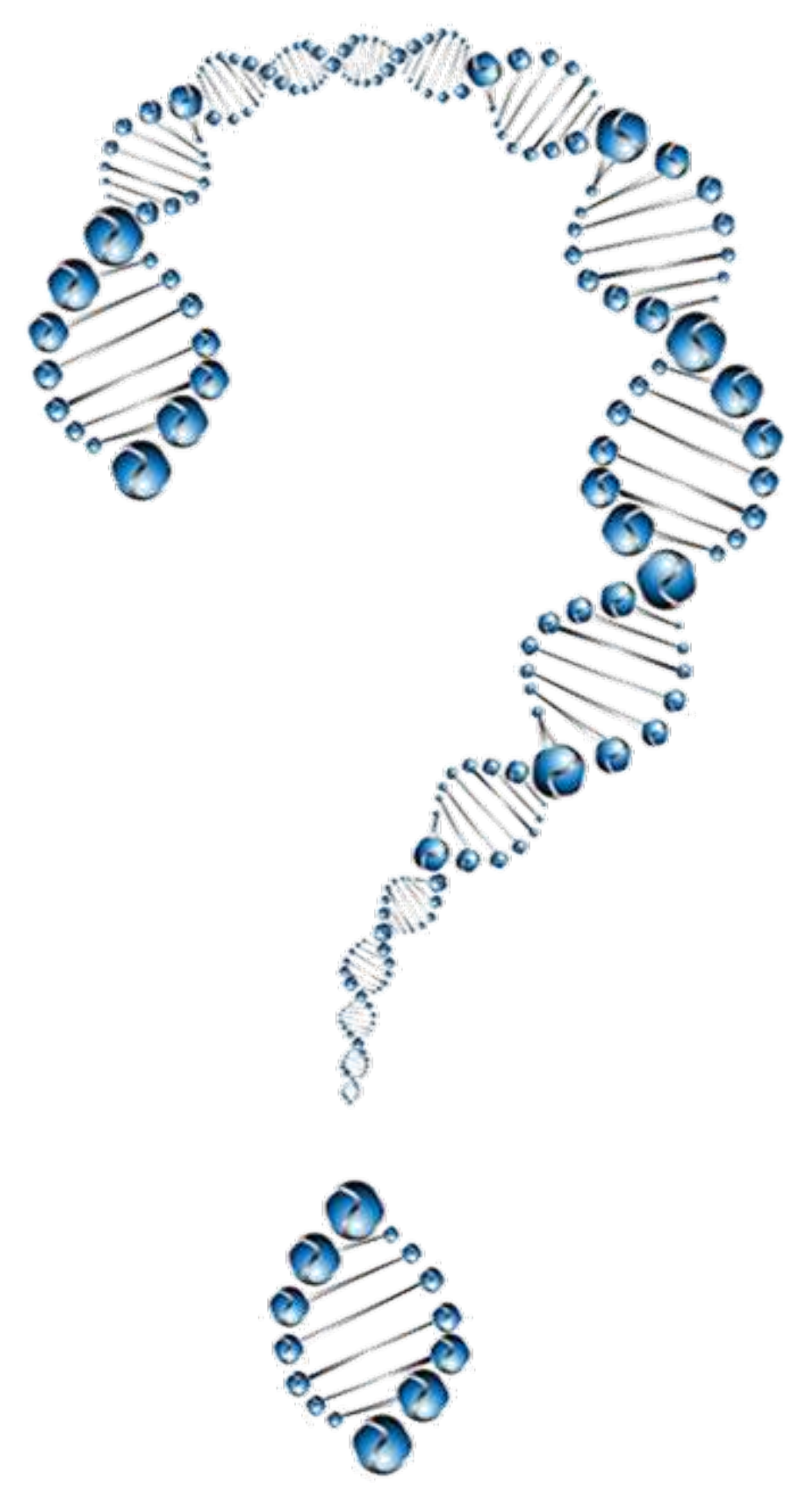

Material to gain a control of thin Nafion ${ }^{\circledR}$

- Direct Nafion ${ }^{\circledR}$ domains during self-assembly

- Provide structural flexibility 


\section{Useful \& Tunable Materials}

For Nafion ${ }^{\circledR}$ film in catalyst layer $(<20 \mathrm{~nm})$

Elastin building blocks

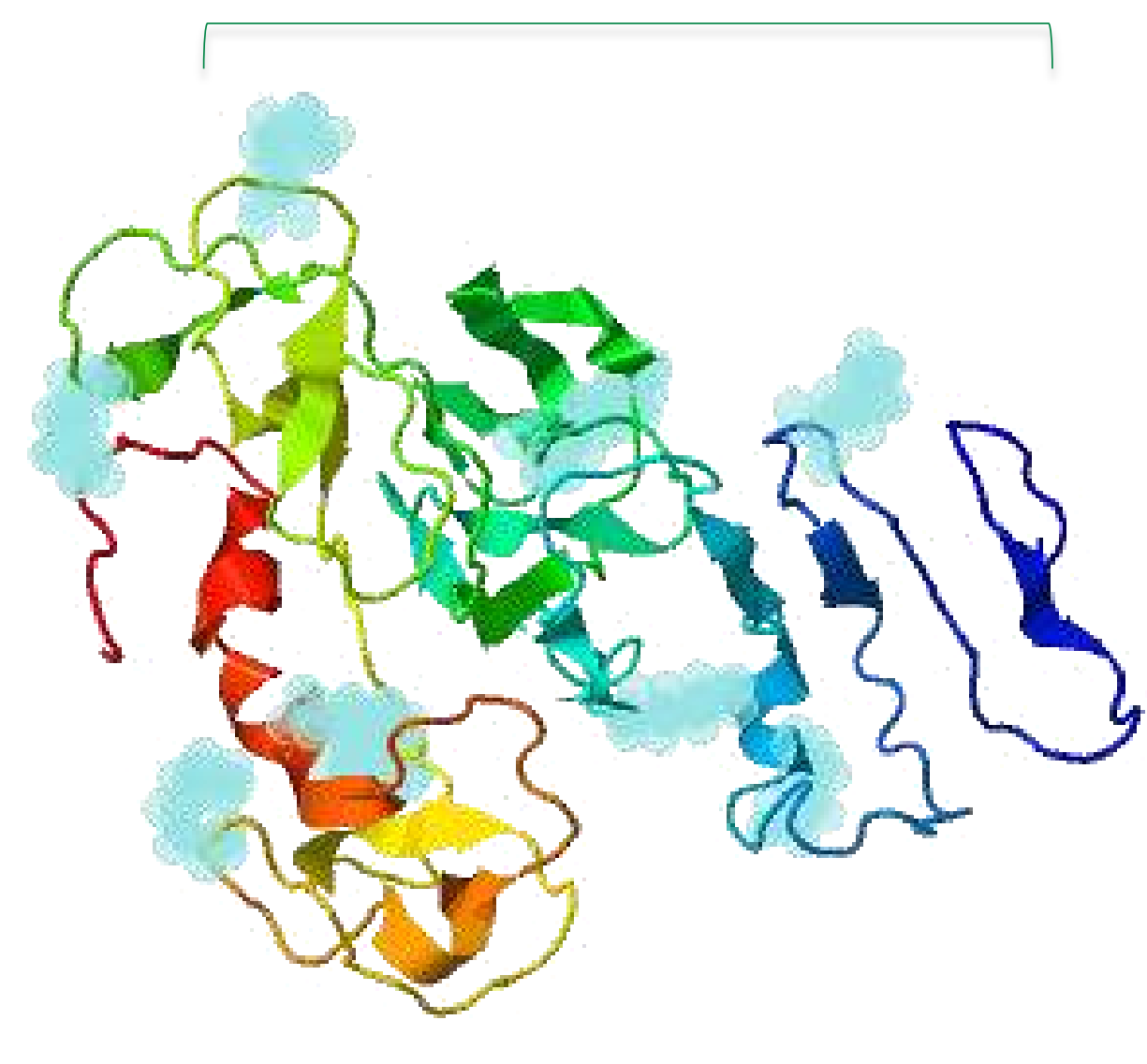

Pt-binding 


\section{Useful \& Tunable Materials}

For Nafion ${ }^{\circledR}$ film in catalyst layer $(<20 \mathrm{~nm})$

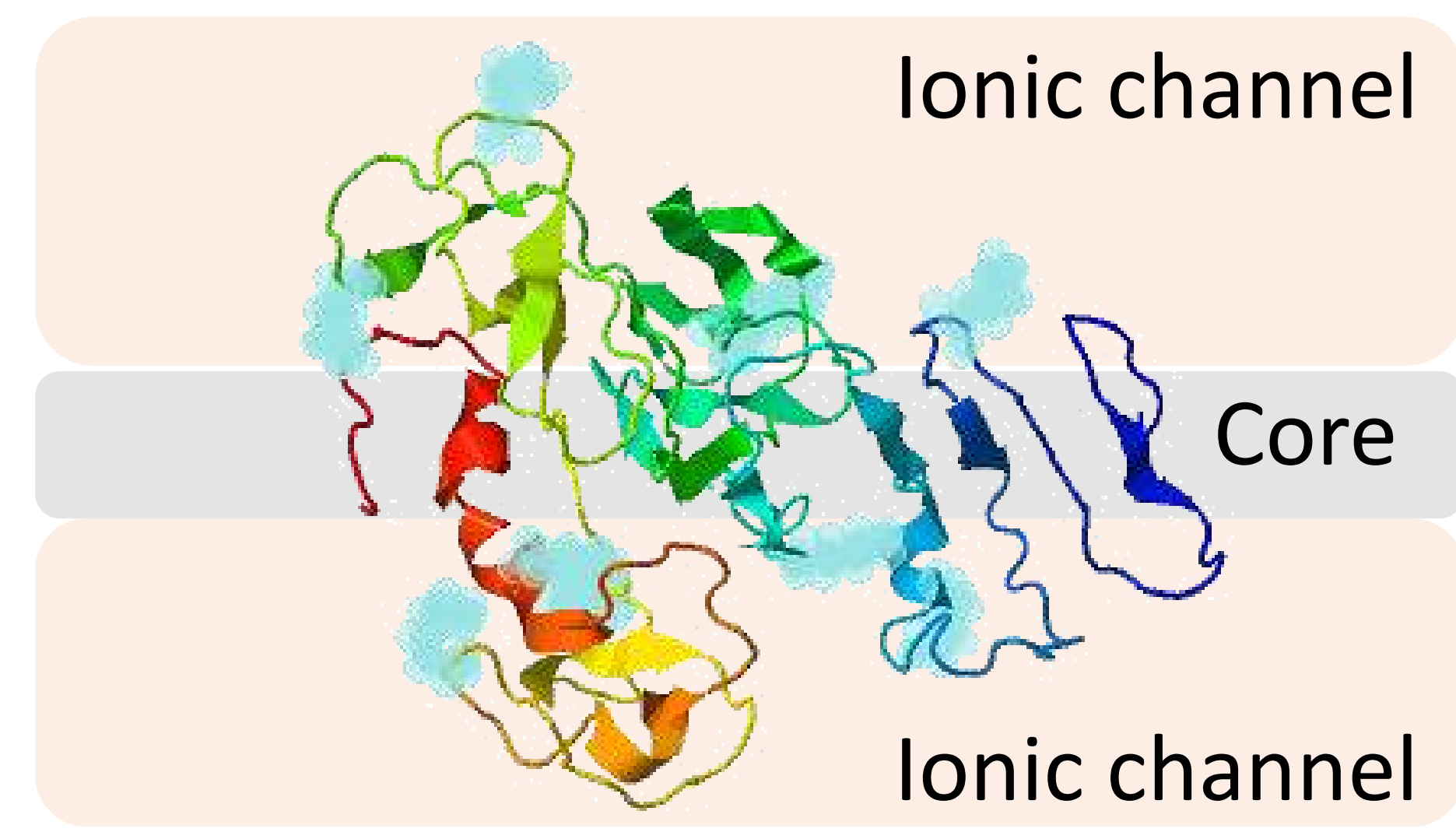

Introducing elastin-like polypeptide

- A domain organizer

- A structural designer 


\section{Lysine Amino Acid Attracts Nafion ${ }^{\circledR}$}

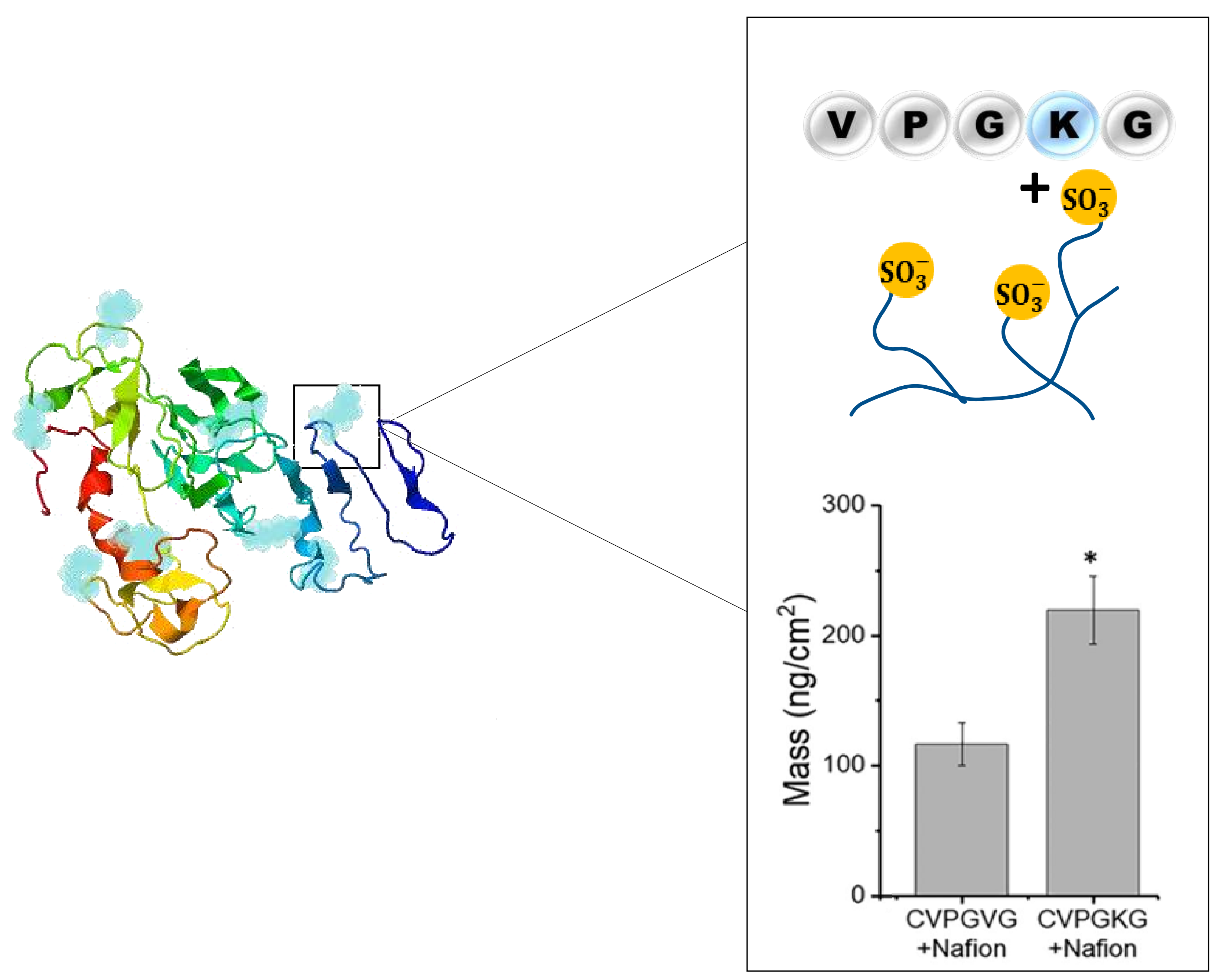

Z. Su, N. Pramounmat, S. T. Watson, and J. N. Renner, "Engineered interaction between short elastin-like peptides and perfluorinated sulfonic-acid ionomer," Soft Matter, 2018. 


\section{Mass Uptake \& Assembling Behavior Quantified by quartz crystal Microbalance (QCM)}

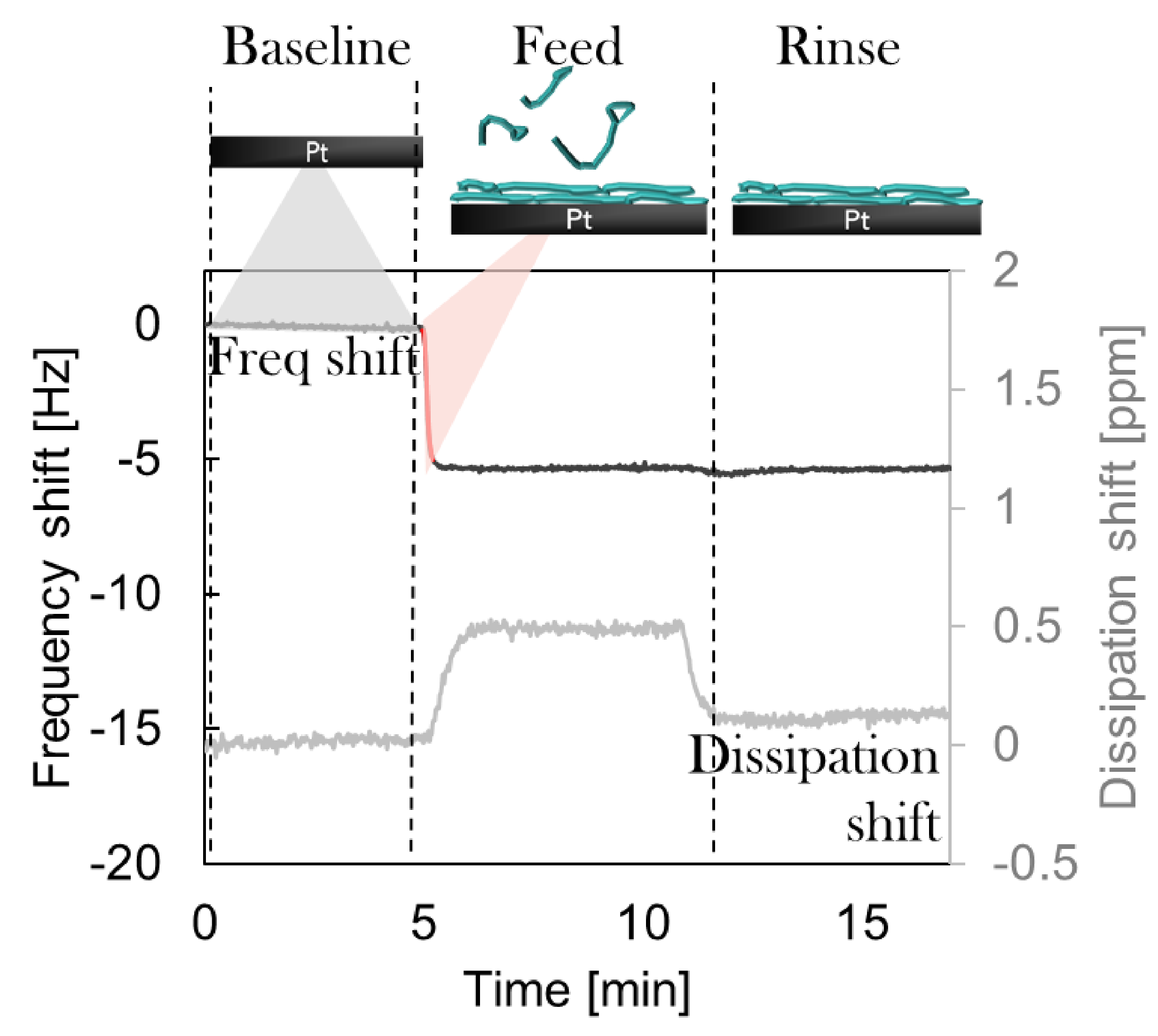




\section{ELP Affects Nafion Assembly}

Without ELP, strong binding interaction of lower uptake in Nafion ${ }^{\circledR}$ on bare Pt
With ELP, strong initial binding is followed by softer binding.

Nafion ${ }^{\circledR}$ uptake was higher.

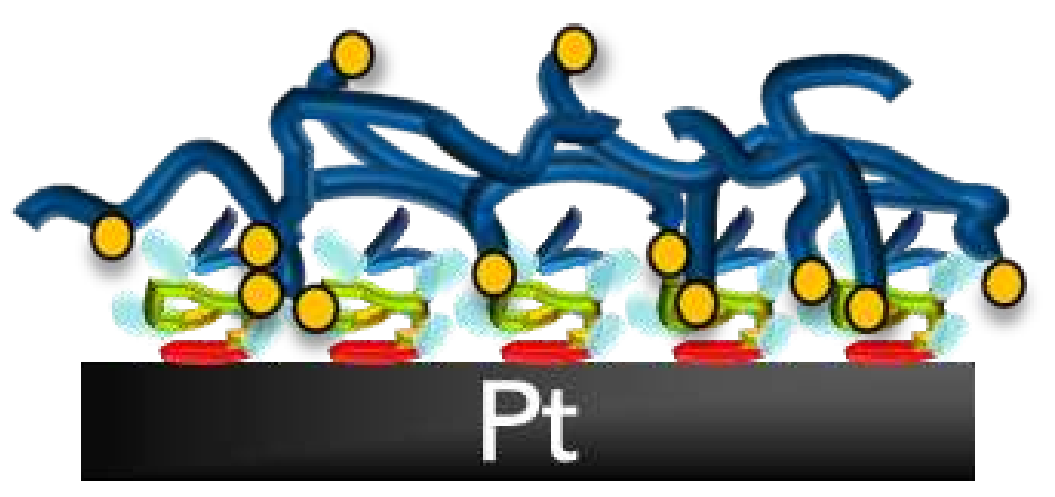

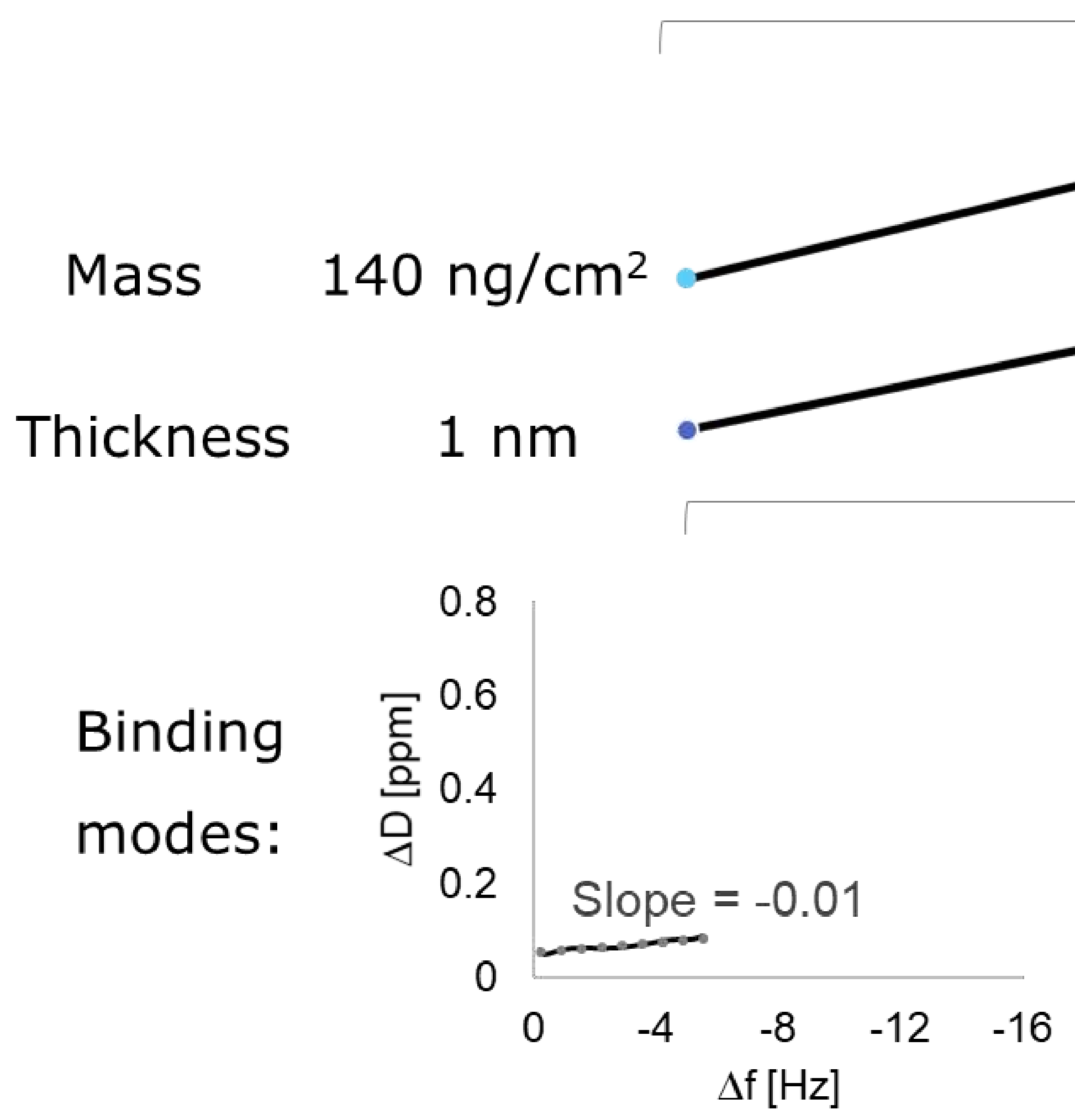

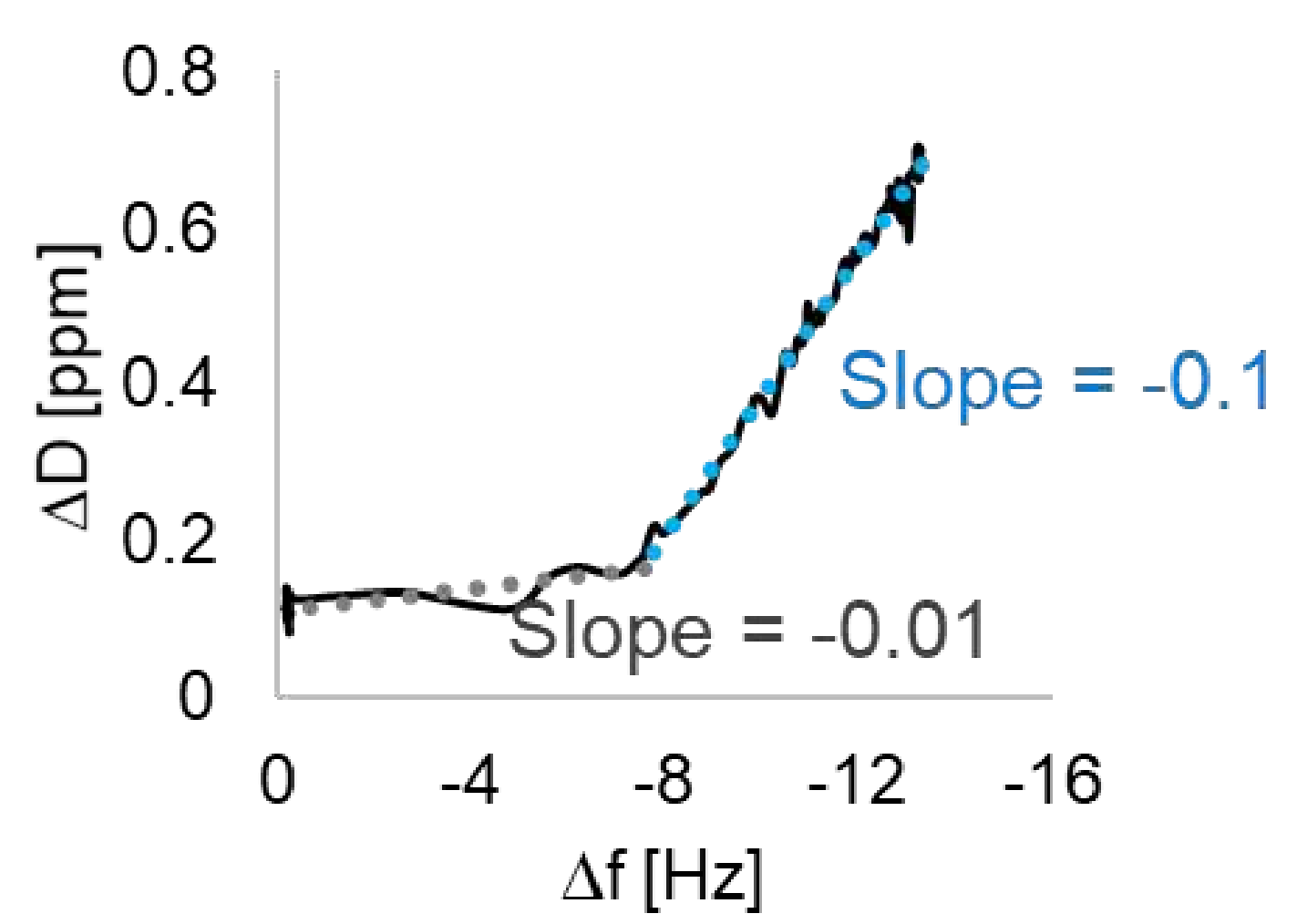




\section{ELP Affects Nafion ${ }^{\circledR}$ Domains Arrangement}
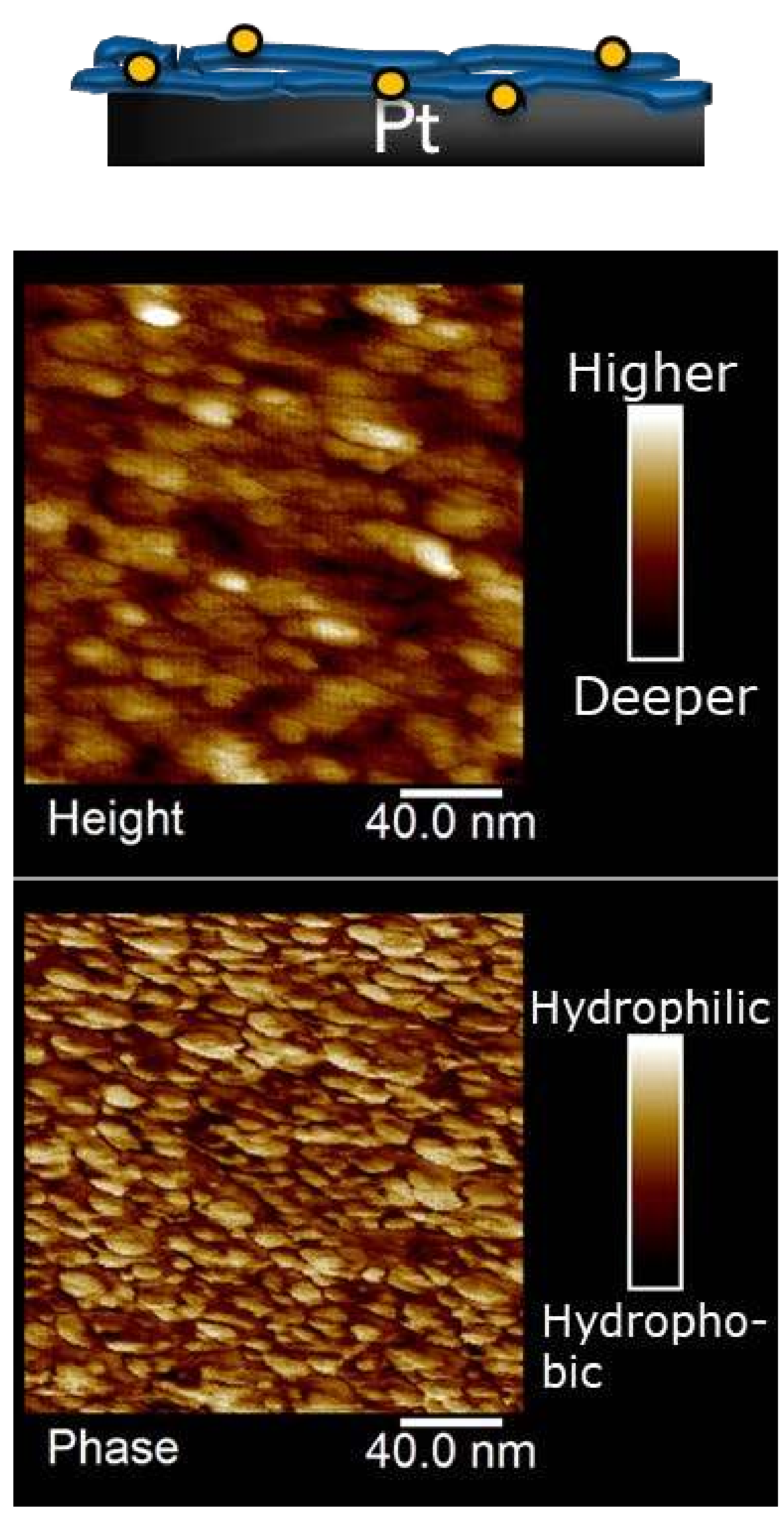
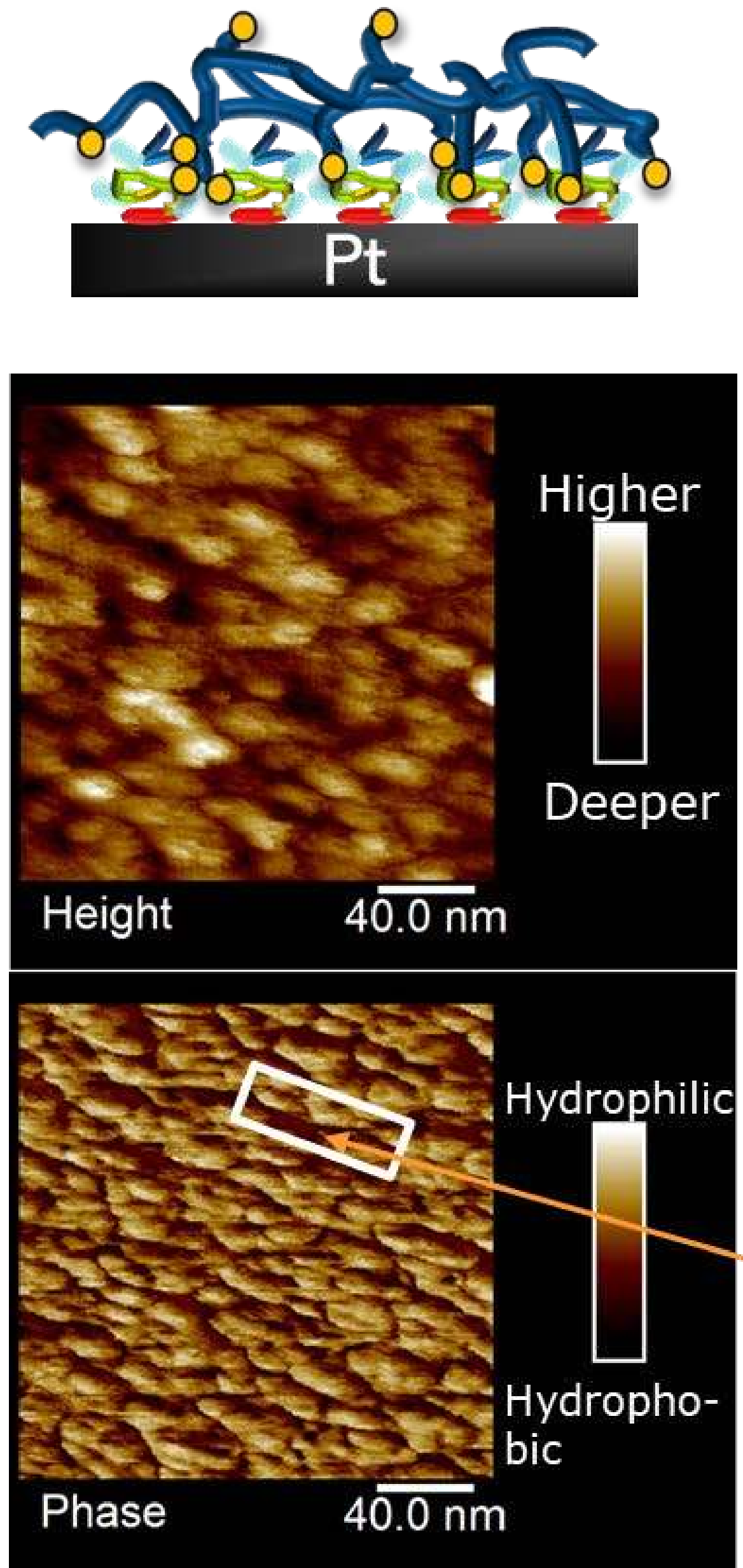

Nafion ${ }^{\circledR}$ with ELP on Pt shows smoother, more elevated surface

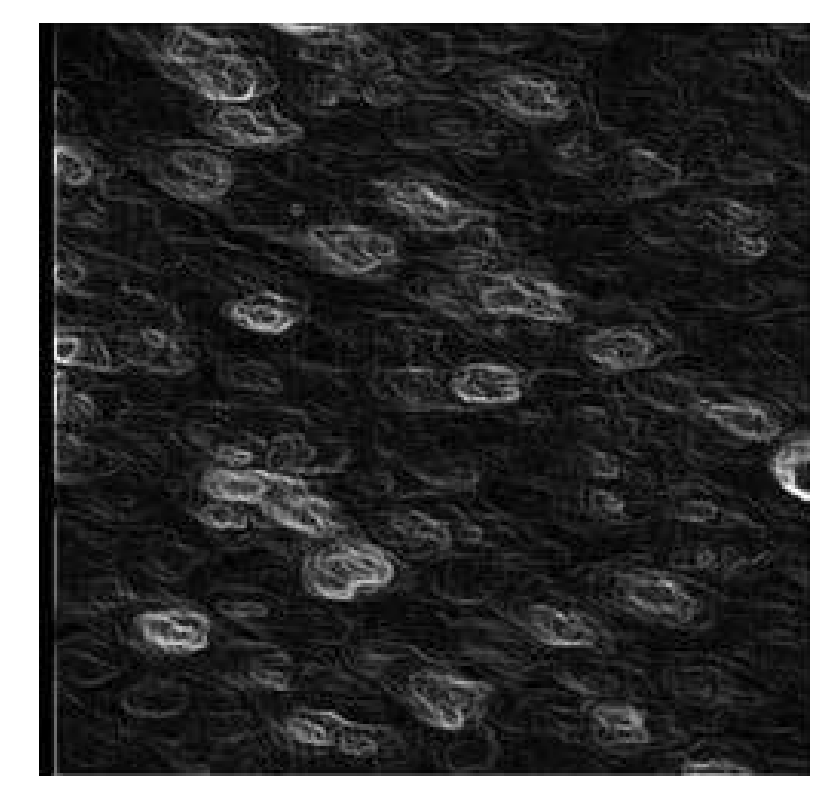

N. Pramounmat et al. Controlling the Distribution of Perfluorinated Sulfonic Acid Ionomer with Elastin-like Polypeptide. ACS Appl. Mater. Interfaces 11, 43649-43658 (2019). 


\section{Phase Separation Occurs in ELP:}

\section{GISAXS suggested ELP induces phase separation in Nafion ${ }^{\circledR}$}

Grazing incident small angle scattering (GISAXS) data collected by Ahmet Kusoglu at Berkeley National Laboratory
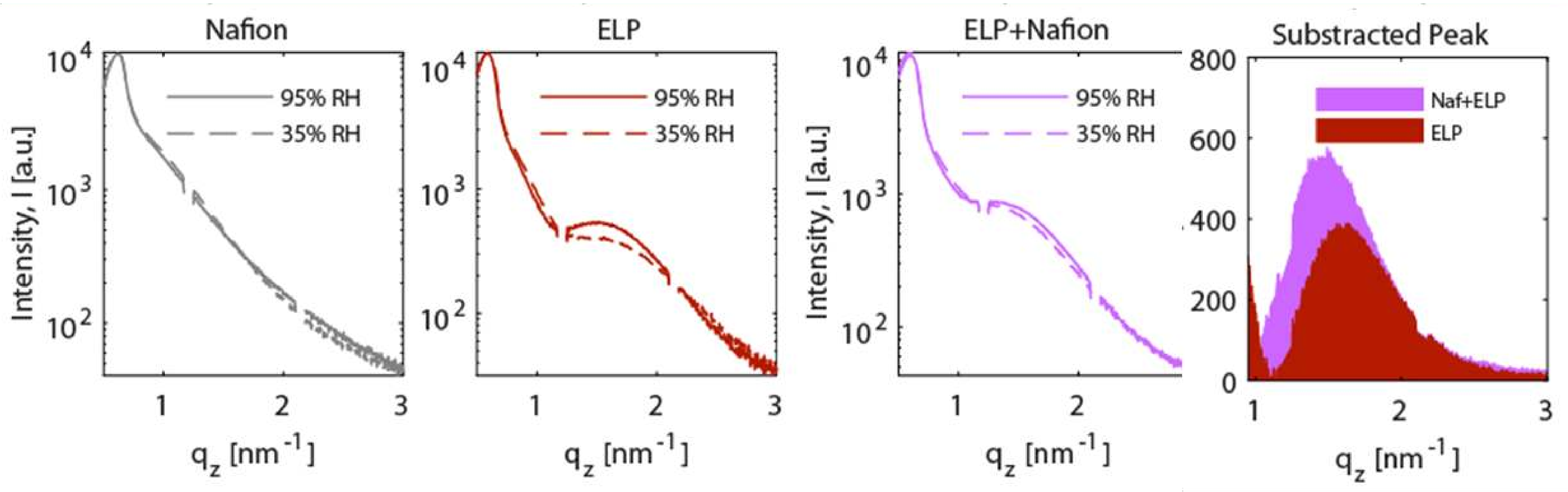

\section{Clear difference} in domain spacing of Nafion ${ }^{\circledR}$ on ELP-Pt compared to Nafion on bare Pt
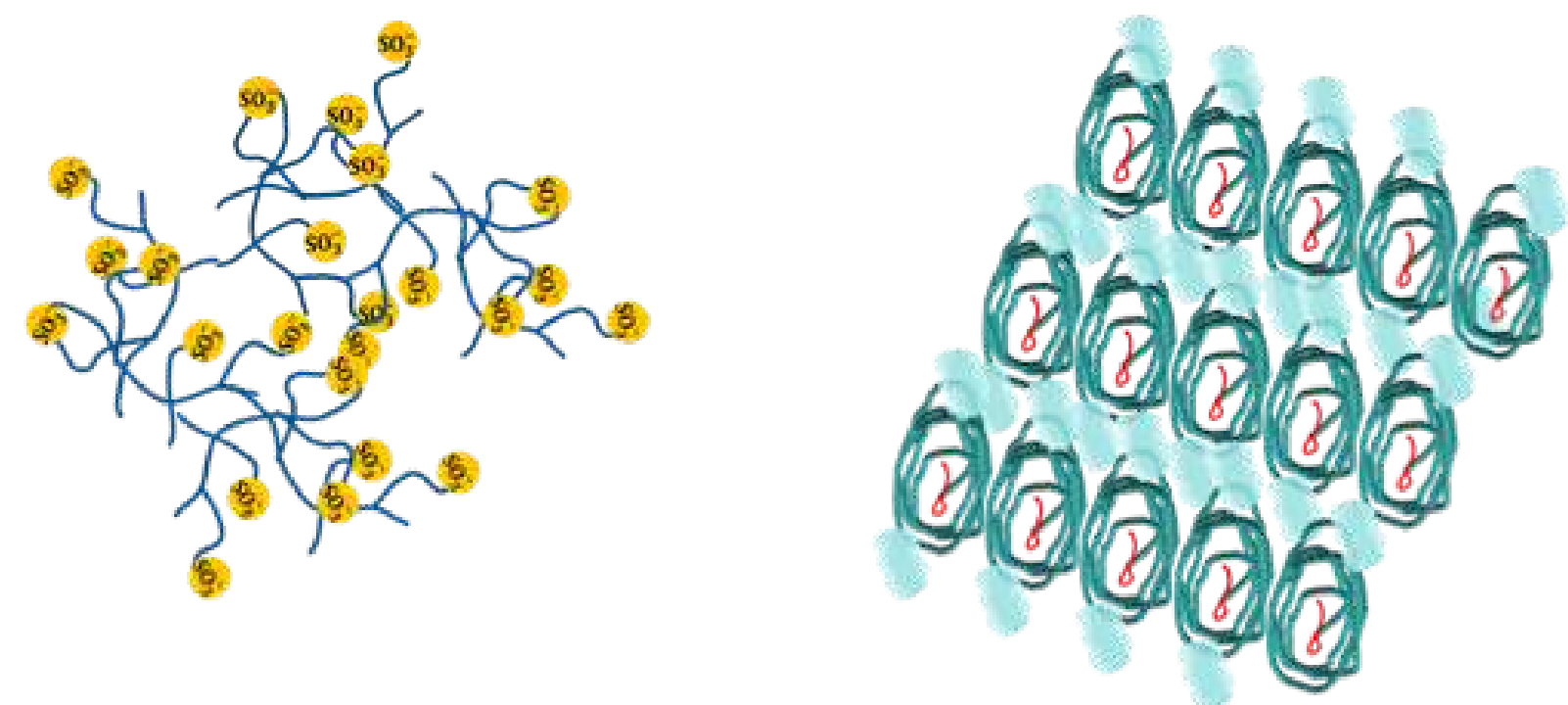

Random Phase separated

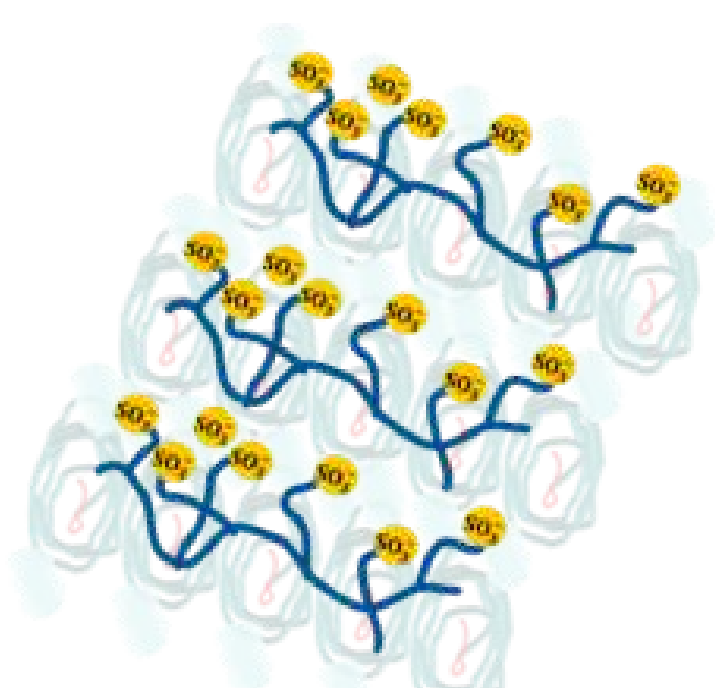

Phase separated 


\section{Can ELP control actual electrode?}

Practicality test with catalyst layers (Pt particles, Nafion ${ }^{\circledR}$, solvent, ELP)

Conventional
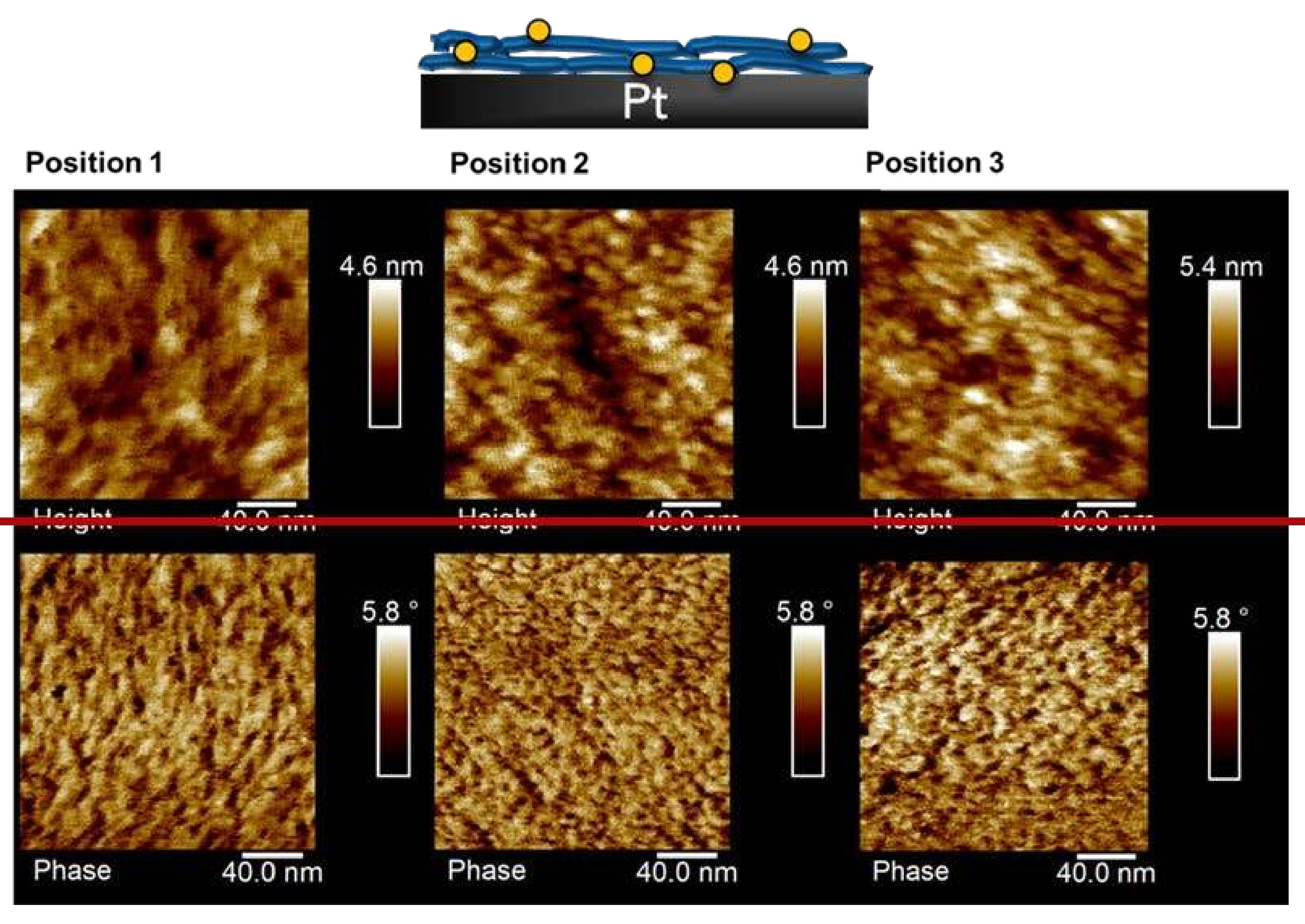

With ELP

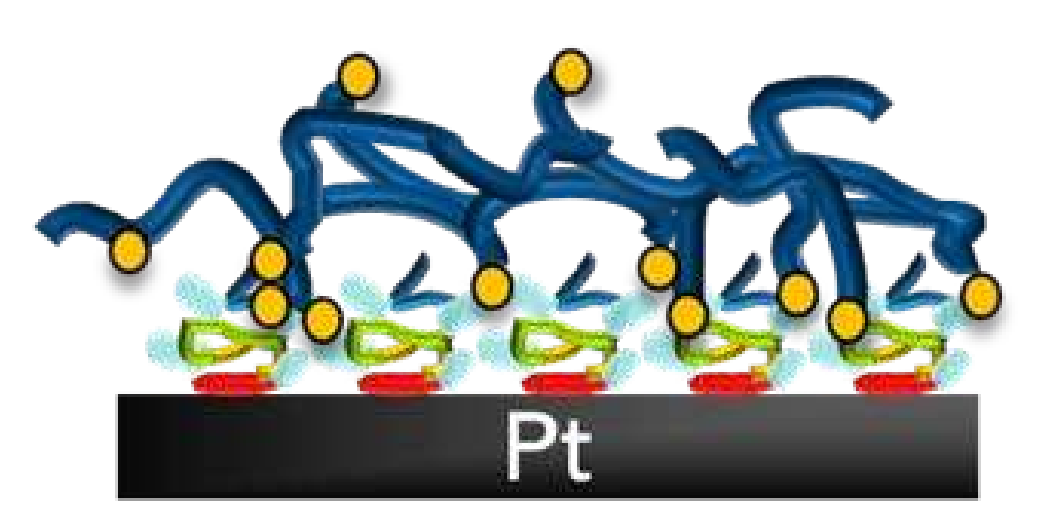

Position 2

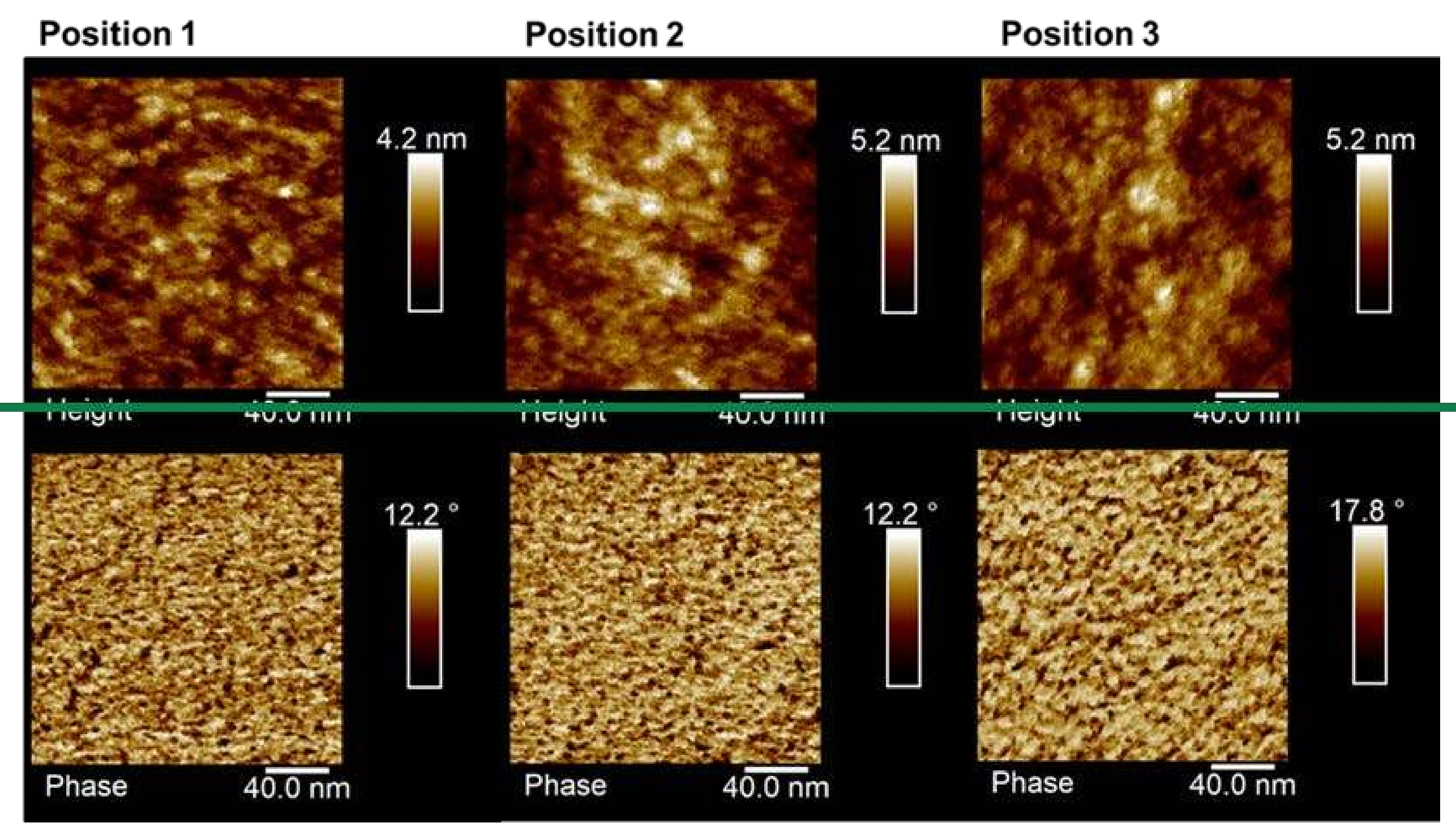

ELP controls phase distribution in substrates of electrode 


\section{Thank you!}

(ESS) + ToYing ma

W/ CASEWESTERNRESERVE

U U I V E R S I T Y EST. 1826

Nuttanit (Natalie) Pramounmat

nxp248@case.edu 